\title{
UNA ALTERNATIVA AL TRABAJO SOCIAL INSTITUCIONALIZADO: EL TRABAJO SOCIAL EN LA EMPRESA PRIVADA
}

\section{YOLANDA DOMENECH LÓPEZ}

Profesora ayudante. Area de Trabajo Social y Servicios Sociales.

Universidad de Alicante.

JUAN CARLOS GÓMEZ DÍAZ

Licenciado en Ciencias Económicas y Empresariales.

Universidad de Alicante.

\section{INTRODUCCIÓN}

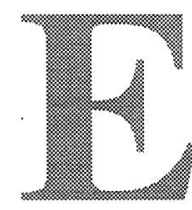

1 Trabajo social en la empresa privada constituye, hoy en día, una verdadera alternativa al Trabajo social de siempre, el Trabajo social institucionalizado.

Con este artículo pretendemos mostrar funciones propias y adecuadas al Trabajo social en la empresa privada. Así como los beneficios que obtendría tanto el empresario como el trabajador y la sociedad en general.

La mayoría de nuestros empresarios nunca se han planteado la existencia del Trabajo social en las empresas, no encontrando el papel que un trabajador social podía desempeñar.

En las grandes empresas, el departamento de recursos humanos es el encargado de dirigir al personal de la empresa, asumiendo funciones tales como ${ }^{1}$ :

1. LA GESTIÓN DEL RENDIMIENTO OPERATIVO:

- Acomodación de los recursos y las estructuras.

- Flexibilización de las relaciones de trabajo.

- Personalización del sistema de retribución.

- Revisión de los conceptos salariales.

2. EL ESTUDIO DE LA INNOVACIÓN Y LA FLEXIBILIDAD:

- La correcta planificación de las necesidades del personal. 
- La formación del personal.

- La adaptación de las estructuras productivas.

- El achatamiento de la pirámide organizativa.

3. CONSEGUIR LA ADHESIÓN DEL PERSONAL:

Es en este último aspecto donde vemos una mayor relevancia del trabajador social, ya que es en este ámbito donde existe un interés creciente de ampliar, desarrollar y potenciar los recursos humanos, puesto que, aunque algunos todavía no se han convencido, el personal humano de la empresa es de vital importancia para el funcionamiento de ésta.

No podemos olvidarnos de la aplicación del enfoque sistémico en la gestión de los recursos humanos. Aunque esta aplicación no se encuentra muy extendida, supone una herramienta eficaz, ya que tendríamos en cuenta cada una de las partes de la empresa como un todo.

Nuestra propuesta trataría de contar con la presencia del trabajador social en la empresa privada, incorporándolo dentro del departamento de Recursos Humanos. La figura del trabajador social, dentro de este departamento, compartiría funciones propias de los recursos humanos (descritas anteriormente), al trabajar en equipo con los demás miembros y al asumir funciones nuevas y específicas del Trabajo social.

En el presente artículo trataremos el papel del Trabajo social, realizando el recorrido de un trabajador, desde su incorporación hasta su salida de la empresa. Para ello, hablaremos de problemas que pueden darse en la vida de una empresa, tanto generados en ella o no. Al fin y al cabo problemas del trabajador que pueden repercutir directamente en su rendimiento. Asimismo, intentar «vender» la figura del Trabajo social en la empresa privada, dejando reflejados los beneficios que pueden obtenerse.

\section{LA LLEGADA A LA EMPRESA}

Cuando un trabajador se incorpora a la empresa tras numerosas pruebas para conseguirlo, hablaremos del fenómeno de la inducción, fenómeno que puede ser descrito como la fase «post-incorporación» de una persona a su puesto de trabajo. El problema que vemos en esta fase es que, a menudo, cuando alguien se incorpora al trabajo, la inducción se realiza en su sentido más negativo: el de investigar asfixiantemente a una persona. Investigarla legalmente, controlarla en sus horarios, ritmos de trabajo..., y, casi siempre, abandonarla en su tarea, no realizar un acompañamiento durante los primeros días, comenzando así a establecerse una relación negativa en la empresa. Esta relación, si no se logra establecer durante la primera fase del trabajador en la empresa, será difícil recuperarla, ya que el contrato psicológico por el que am- 
bas partes se comprometen nunca se llegará a formar, pues implícitamente la relación estará llena de miedos y prejuicios.

Señalamos, asî, que la comunicación entre el nuevo empleado y su empresa (tanto con sus superiores como con sus compañeros) no seguirá un proceso de ida y vuelta (feed-back) y se limitará a acatar las órdenes que se le imponen.

¿Qué sucede entonces?

Estos problemas de comunicación derivan en problemas de relación tanto con los compañeros como con los jefes, lo que dificulta, cada vez más, esas relaciones. Llegamos a tener, de esta manera, lo que se ha denominado empleado problema, al cual se le plantea una solución: EL DESPIDO.

Nosotros proponemos otra solución. Por un lado, ver dos sujetos activos: el nuevo trabajador y la empresa. Por otro, tener un objetivo claro: cambiar esta relación descrita anteriormente.

El trabajador social, dentro de esta etapa, juega un papel muy importante, produciéndose la primera toma de contacto con el trabajador.

Entre las funciones que puede desempeñar destacamos:

- Acoger al trabajador

- Asignar un tutor para los primeros días de trabajo.

- Realizar su ficha social, para ir elaborando su historia social: estudio y diagnóstico de la situación laboral y social.

- Mediar entre la empresa y el trabajador.

- Realizar un plan de trabajo con el trabajador, en el que se contemple formación, aspiraciones, posibilidades de promoción, etc.

De este modo, el trabajador social conseguirá una buena adhesión del trabajador a la empresa. El trabajador se sentiría como parte activa de la empresa, siendo escuchado y respaldado por la misma, lo que le permitirá, gracias a esta primera fase, construir poco a poco su espacio profesional. La empresa obtendría así un nuevo trabajador motivado en su tarea, y, al fin y al cabo, en conseguir los objetivos de la empresa.

\section{EN LA EMPRESA}

Dentro de la empresa, es necesario el conocimiento y revisión de su clima social. Al hablar de clima social hacemos referencia a «las cualidades, atributos o propiedades relativamente permanentes de un ambiente de trabajo concreto que son percibidas, sentidas o experimentadas por las personas que trabajan en él y que influyen sobre su conducta». ${ }^{2}$ 
Nos planteamos, así, cómo conocer el clima social de la empresa. Se han diseñado diversos métodos de diagnóstico periódicos, pero que, al no reflejarse luego en acciones concretas, no han servido para mucho.

Desde el Trabajo social, proponemos nuestro método de trabajo. Método que incluye un estudio del personal laboral de la empresa (a base de recorrer los lugares de trabajo con una comunicación efectiva y empática); un diagnóstico del clima social de la empresa, analizando y tratando la información recogida, y una planificación y evaluación del proyecto de trabajo para crear o mantener ese clima social.

Todo este trabajo debe concretarse en actuaciones palpables y evaluables por todos. Las técnicas que proponemos serían técnicas de recogida de datos, la entrevista y dinámicas de grupo donde se fomentará uno de los principios del Trabajo social: la participación.

Del análisis de este clima, el Trabajador social debe ir más allá. De una buena actuación profesional tendremos:

1. Conocimiento y análisis de problemas generados en la empresa (estrés, absentismo laboral, traslado de personal...).

2. Detección de otros problemas (familiares, personales...) que inciden en el funcionamiento de la empresa y el rendimiento.

3. Identificación de colectivos en situación de riesgo, para efectuar una prevención eficaz.

Realizando estos estudios periódicos del clima social en la empresa, el trabajador social detectará problemas con los que deberá trabajar directamente con y desde la empresa y otros que, aunque no tengan su solución en la empresa, el Trabajador social deberá hacer de puente informativo con el exterior.

\subsection{Estrés laboral}

Podemos definir el estrés como una sensación desagradable derivada de pensamientos negativos sobre nuestro entorno, generadora de altas dosis de tensión.

Los factores ambientales y psicológicos afectan directamente sobre los trabajadores de la empresa.

La empresa como tal puede ser la causante de producir estrés, tal y como se refleja en los cuadros que a continuación se presentan.

Podemos señalar como elementos comunes de factores desencadenantes de estrés:

1. Falta de autonomía del trabajador sobre el control de su trabajo.

2. Imposibilidad de utilizar sus conocimientos para desarrollar novedades.

3. Ausencia de reconocimiento de su valía. 
CUADRO 1: LA EMPRESA COMO FUENTE DE ESTRÉS.

\begin{tabular}{|c|c|}
\hline $\begin{array}{l}\text { CONDICIONES LABORALES } \\
\text { GENERADORAS DE ESTRÉS }\end{array}$ & $\begin{array}{l}\text { INTERPRETACIONES PERSONALES } \\
\text { GENERADORAS DE ESTRÉS }\end{array}$ \\
\hline Mandos con exceso de subordinados. & Dificultad para delegar. \\
\hline Jornadas laborales muy largas. & "Job-addict". \\
\hline Frecuentes desplazamientos. & $\begin{array}{l}\text { Alteraciones debidas a frecuentes } \\
\text { desplazamientos. }\end{array}$ \\
\hline Jornadas de horarios rotativos. & $\begin{array}{l}\text { Incapacidad para adaptarse a cambios debidos al } \\
\text { horario. }\end{array}$ \\
\hline Problemas en el clima laboral. & Malas relaciones con compañeros determinados. \\
\hline Exceso de trabajo. & Mala planificación (del tiempo y de prioridades). \\
\hline Exceso de responsabilidad. & Asunción de competencias ajenas. \\
\hline Constantes juicios y evaluaciones. & Perfeccionismo exagerado. \\
\hline Falta de apoyo de superiores. & Falta de reconocimiento de la propia valía. \\
\hline Ordenes contradictorias. & $\begin{array}{l}\text { Dificultad para diferenciar lo urgente de lo } \\
\text { inmediato. }\end{array}$ \\
\hline Tener varios jefes. & Déficits asertivos. \\
\hline $\begin{array}{l}\text { Introducción de nuevas técnicas y } \\
\text { cambios frecuentes. }\end{array}$ & Falta de flexibilidad y resistencia al cambio. \\
\hline Cargos públicos (hablar a un auditorio) & Fobias sociales. \\
\hline $\begin{array}{l}\text { Crisis económica, reducción de } \\
\text { plantillas, contratos temporales... }\end{array}$ & $\begin{array}{l}\text { Pluriempleo y/o vivencia de inestabilidad en el } \\
\text { puesto de trabajo. }\end{array}$ \\
\hline Exceso de control y supervisión. & Inseguridad, búsqueda constante de supervisión. \\
\hline La promoción de la competitividad. & Tendencia a la rivalidad. \\
\hline $\begin{array}{l}\text { Medios excesivamente organizados o } \\
\text { excesivamente desorganizados. }\end{array}$ & $\begin{array}{l}\text { Personas excesivamente rígidas o excesivamente } \\
\text { caóticas. }\end{array}$ \\
\hline
\end{tabular}

Todo ello puede repercutir en el comportamiento del trabajador .

El trabajador social puede, junto con la empresa y con el trabajador afectado, desarrollar un trabajo de seguimiento donde se reduzcan todos aquellas fuentes de tensión generadoras de estrés. Deberá informar de los riesgos físicos, psíquicos y sociales que pueden llegar a producir conductas estresantes producidas por la empresa y que se deban a aspectos organizacionales, a la vez que actuar sobre los casos ya detectados.

De esta ayuda profesional, los beneficios, tanto para el empresario como para el trabajador, son claros: se disminuyen las tensiones en la empresa, se reducen conflictos laborales, disminuye el absentismo, se 
potencia la motivación de los empleados y se reducen, para el trabajador, los problemas físicos y psíquicos derivados del estrés laboral.

\section{CUADRO 2: CONSECUENCIAS DEL ESTRÉS.}

\begin{tabular}{|l|l|}
\hline FÍSICAS & PSICOLÓGICAS \\
\hline - Cefaleas. & - Ataques de ira. \\
- Ulceras. & - Depresión. \\
- Asma. & - Déficits de la autoestima. \\
- Alteraciones menstruales. & - Fobias, miedos absurdos. \\
- Alteraciones de la sexualidad. & - Culpabilidad. \\
- Hipertensión. & - Alteraciones en las relaciones sociales. \\
- Riesgo de ataque cardíaco. & - Insomnio, pesadillas. \\
- Ataques de apoplejía. & - Disminución de la atención, rendimiento y \\
- Cáncer. & memoria. \\
& - Adicción a sustancias como: alcohol, \\
- Ahogos y palpitaciones. & tabaco, medicamentos y drogas. \\
- Cansancio crónico. & - Ataques de ansiedad. \\
\hline
\end{tabular}

FUENTE: Revista Capital Humano, n. ${ }^{\circ} 52$. Enero de 1993, pág. 52.

\subsection{Toxicomanías}

El consumo de drogas en España es un fenómeno preocupante para la sociedad. Lamentablemente, sólo se asocia con la delincuencia y la inseguridad ciudadana, sin embargo, los datos y encuestas nos ofrecen una visión muy diferente.

En la empresa, el consumo de drogas como el alcohol, el tabaco, y otras sustancias, está presente, alcanzando un alto índice de consumo. Las consecuencias para la empresa son siempre negativas, pero es en el trabajador donde se manifiestan tanto de forma física, como psíquica y social.

El consumo de alcohol es, sin duda, uno de los problemas más importantes con los que ha de enfrentarse una empresa. Las razones por las que «el consumo de alcohol en la empresa» es cada vez más preocupante, pueden resumirse en:

- Es causa de numerosas bajas laborales.

- Origina miles de accidentes de trabajo al año. 
- Se diagnostican cifras elevadas de enfermos de cirrosis hepática.

- A él se deben numerosos accidentes de trabajo indirectamente relacionados con el ámbito laboral.

- Produce un aumento de los enfrentamientos producidos en la empresa.

- El rendimiento laboral se reduce notablemente cuando el individuo se encuentra bajo el efecto de alcohol.

- Alto índice de absentismo, directamente proporcional con el consumo de alcohol.

Según la Organización Internacional del Trabajo (O.I.T.), el total de pérdidas que sufren cada año las empresas españolas, por los efectos del consumo de drogas y alcohol en los centros de trabajo, asciende a doscientos mil millones de pesetas, además, el consumo de ambos productos es la causa del $30 \%$ de los accidentes laborales mortales y del $40 \%$ de los expedientes disciplinarios a trabajadores (datos de 1993).

La solución aportada por la empresa viene siendo el despido, solución que ocasiona graves costes para el empresario, ya que ha de pagar una indemnización, si procede, y cargar con los gastos de buscar y formar un nuevo trabajador. Además, con el despido, el coste para el trabajador es evidente. Sin un trabajo, el problema de la bebida puede agravarse, siendo más difícil su futura incorporación al mundo laboral, no llegando nunca a solucionar su problema con el alcohol.

La alternativa al despido, desde nuestra óptica, se centraría en:

- Realizar labores de detección de síntomas.

- Informar al trabajador sobre los efectos de alcohol y drogas, y de sus riesgos laborales.

- Atender los casos detectados.

- Crear, dentro de la empresa, grupos de autoayuda.

- Ejercer de puente con el exterior (recursos existentes).

- Realizar evaluaciones periódicas para que la empresa participe en la recuperación de sus trabajadores.

Con la actuación del Trabajador social (descrita anteriormente) se reduciría al absentismo laboral, las bajas médicas, los accidentes laborales y, en último término, el despido, ya que el trabajador reconocería su dependencia e iniciaría un tratamiento.

\subsection{Absentismo laboral}

El absentismo laboral es un problema que afecta prácticamente a todas las empresas.

Podemos distinguir dos tipos de absentismo laboral:

1. Justificado. Es decir, el trabajador que no puede acudir al centro de trabajo. Dentro de este grupo distinguimos, por un lado, el 
absentismo por bajas de enfermedad, tanto físicas como psíquicas, es decir el absentismo «legítimo», y, por otro, los trabajadores que no acuden al trabajo por problemas no legitimados por el empresario, tales como alcohol, drogas, estrés, etc., que suponen un verdadero impedimento para asistir al puesto de trabajo.

2. No justificado. Cuando no existe impedimento alguno y es el trabajador el que pone excusas e inventa razones para no acudir, o simplemente no acude. En estos casos, la falta de motivación de los trabajadores es la principal razón, los trabajadores no comparten los objetivos de la empresa y no se sienten como elementos importantes de la misma.

Para el trabajo social, es de suma importancia involucrar al trabajador en la empresa, haciéndole partícipe de sus objetivos, así como motivándole al reconocer su importancia en la empresa. El trabajador social detectará posibles síntomas de desmotivación, así como factores externos que afecten al trabajador, realizando, de este modo, un trabajo de conexión con el exterior.

\subsection{Traslado de personal}

Durante la vida de una empresa es frecuente encontrar personas que hayan sido trasladadas, así como trabajadores que próximamente vayan a dejar su puesto para ocuparlo en una empresa situada en otra ciudad.

El traslado de personal ha sido clasificado como un serio problema para la empresa, pero ¿qué pasa con el trasladado?... Al hablar de problema para la empresa, hablamos indirectamente de problema para el empleado, ya que son sus problemas de adaptación, derivados del traslado, los que van a repercutir en la empresa.

Desde la empresa emisora y desde la receptora del trabajador se puede realizar un trabajo eficaz para que los problemas sean menores. Partimos de una necesidad latente: «la necesidad de un asesoramiento global al trasladado y su familia» ${ }^{3}$, por lo tanto, se ha de preparar el traslado. El trabajador social debe ver en el trasladado y su familia, una posible situación de vulnerabilidad. Para ello, deberá realizar un trabajo de seguimiento con las familias.

Cuando el traslado no es voluntario, se agravan aún más los problemas. Las familias se han de enfrentar a un cambio y a menudo muy rápido.

GOLDMAN, Claudia y otros.;»Traslado de personal: un serio problema para la empresa».

Capital Humano.n³5. Junio de 1991. 
Se habla del trauma de la «movilidad», que conlleva sentimientos de confusión, negación, enfado, resentimiento, y puede desembocar en una depresión. No sólo es el trabajador el que debe asumir su nueva situación laboral; toda la familia se ve afectada por el traslado, ya que puede llevar a la pérdida del trabajo del cónyuge, separación del cónyuge e hijos, nuevas amistades, cambio de colegio, nueva ocupación del tiempo libre...

El trabajador social en la empresa puede ayudar a preparar el traslado, anticipándose a los efectos de crisis y apoyando al trasladado y a su familia para buscar juntos un nuevo proyecto de vida. Además, desde la empresa receptora, se podrá trabajar en equipo, estando coordinadas ambas empresas.

Un traslado que resulte un fracaso, o incluso que desemboque en enfermedad, no reporta ningún beneficio a la empresa, la cual puede, incluso, llegar a perder al empleado.

\subsection{Integración laboral de minusválidos}

La integración laboral de minusválidos, en la actualidad, no deja de ser algo irreal si hablamos de integración en la empresa ordinaria.

Los estudios demuestran que la mayoría de este colectivo posee unas posibilidades de trabajo restringidas a los talleres ocupacionales y a centros especiales de empleo. Así, con este panorama, la alternativa laboral queda muy limitada y la empresa ordinaria acoge a muy pocos trabajadores con algún tipo de minusvalía.

Desde nuestra perspectiva, nos centramos en la empresa ordinaria, teniendo ésta su función social orientada en los principios de normalización, integración social e inserción profesional. Para que estos principios puedan llevarse a la práctica, proponemos que el trabajador social realice un trabajo de seguimiento in situ a los trabajadores con minusvalía y que realicen las entrevistas de acogida y de adecuación al puesto de trabajo ofertado. Se trata de informar, orientar y realizar un trabajo de apoyo en el puesto de trabajo para que, la persona con minusvalía aprenda las tareas que requiere el puesto y aprenda a mantenerlas en el tiempo.

Sobre estas premisas, la empresa vasca Zeharo (plenamente en euskera), viene desarrollando desde 1994 una iniciativa comunitaria en materia de integración laboral de personas discapacitadas. Brevemente, expondremos algunos puntos importantes de esta experiencia:

1. Su objetivo es trabajar por una integración normalizada.

2. Su labor principal es el desarrollo de itinerarios personalizados y realistas de inserción laboral.

3. Ofrecen diversos servicios de información profesional, orienta- 
ción, formación ocupacional y apoyos en la búsqueda activa de empleo.

4. Las partes en las que se divide el programa son:

- Entrevista ocupacional; se trata de obtener información sobre la persona demandante de empleo, perfil ocupacional, disponibilidad, capacidades, valoración de sus aptitudes físicas, psíquicas y sensoriales.

- Orientación profesional; depende de los datos obtenidos en la entrevista; se orientará en una u otra dirección profesional.

- Intermediación entre el demandante y la empresa.

- Adecuación al puesto de trabajo, mediante un trabajo de aprendizaje y de seguimiento.

En Zeharo, esta labor de seguimiento viene siendo desarrollada por un equipo interdisciplinar formado por trabajadores sociales, además de la impartición de cursos adecuados para «enganchar» a las empresas.

Según nuestra opinión, el trabajador social puede colaborar en el diseño del perfil adecuado para un determinado puesto de trabajo y que pueda adecuarse a personas con alguna deficiencia física, psíquica o sensorial. Se trataría de realizar un trabajo de estudio y diagnóstico del demandante y el puesto de trabajo, así como de crear, junto con el trabajador, un proyecto de integración realista.

Con la incorporación laboral de minusválidos, se dota a la empresa de un trabajador apto para el puesto elegido, el empresario obtiene un beneficio fiscal y la empresa cumple una de sus funciones olvidadas: su función social.

\section{LA SALIDA DE LA EMPRESA: PREPARACIÓN A LA JUBILACIÓN}

Uno de los temas que nos preocupa es el tema de la jubilación y lo que ella conlleva; sobre todo, la jubilación anticipada que agrava aún más los problemas con los que se va a enfrentar esa nueva clase social «los jubilados».

La jubilación, actualmente, se desarrolla como un paso brusco de una etapa a otra. Pasar de trabajar a no hacerlo, tener el tiempo ocupado a no tenerlo, etc. Etapa nueva, para la que no se está preparado.

Los principales problemas que afronta el jubilado pueden resumirse en:

- Disminución de ingresos económicos.

Esta disminución de ingresos puede ser causa de numerosos conflictos familiares y conyugales. De pronto se necesita una reestructuración a la nueva situación real; los problemas económicos suelen desembocar en sentimientos de inutilidad al no poder, en numerosas ocasiones, llevar el ritmo de vida anterior. 
- Limitaciones físicas y psíquicas.

Con los años, las enfermedades físicas y mentales pueden aparecer, las manías, las pérdidas de memoria son aspectos que se agravan más debido a la no utilización del tiempo libre. A menudo no se sabe qué hacer y se quedan todo el tiempo en casa, lo que empeora, cada vez más, los rasgos depresivos. Esta tristeza y apatía puede desembocar en una crisis y con ella someter a toda la familia.

- Continuas pérdidas físicas y psíquicas.

Esta etapa de jubilación coincide cuando el jubilado se encuentra solo. A menudo, puede haber pérdidas de seres queridos. $\mathrm{Si}$ falta el cónyuge, se sienten estorbos, y la culpabilidad y las ganas de no vivir se agravan. Coincide también con que los hijos ya no necesitan tanto a los padres y éstos no se sienten útiles.

Todos estos problemas suelen estar en reposo y despertar cuando el individuo ya no sabe qué hacer al levantarse por las mañanas.

Por todo esto, el proponer una preparación a la jubilación desde la empresa y antes de abandonarla.

¿Cómo realizaríamos esta preparación ?

Un programa de preparación a la jubilación consistiría en realizar un estudio de los trabajadores próximos a la jubilación y de sus situaciones personales, analizando sus necesidades, inquietudes, miedos y perspectivas futuras. Realizando junto con los trabajadores un plan de jubilación, de modo que considere los aspectos que les sean de interés.

Un programa que contemple: celebración de conferencias, charlas, grupos de trabajo, entrevistas personales, entrevistas familiares, etc. En ellos se tratará de presentar la jubilación al trabajador, analizando las novedades que conlleva esta nueva situación, informando de sus ventajas, así como advirtiendo los posibles problemas que presenta esta nueva etapa. Se informará sobre aspectos médicos (nuevas enfermedades y su prevención, dietas...); vida en pareja (sexualidad, comunicación...); aspectos jurídicos, económicos, fiscales y de seguridad social; aspectos culturales y de ocio; otras alternativas al trabajo remunerado (voluntariados, asociacionismo, colaboraciones...); y, en definitiva, presentar la jubilación como un nuevo reto a la vida.

Los programas de preparación a la jubilación contarían con la participación, por supuesto, del «pre-jubilado», así como del trabajador social y un equipo de asesores especializados en cada tema (médicos, abogados, economistas, representantes de asociaciones...). También consideramos muy importante el contar con la participación de exempleados, jubilados anteriormente, que hayan o no participado en programas anteriores.

El empleo de estos programas se proyecta en un beneficio a la hora de mantener mejores relaciones socio-laborales entre empleado y em- 
presario antes de la jubilación. Destacamos la posibilidad de crear vínculos de colaboración con el personal una vez jubilado, es decir, «comités de expertos» que pueden seguir asesorando a la empresa. Además, estas buenas relaciones permitirían negociar más fácilmente la jubilación anticipada y el trabajador mantendría alto su sentimiento de utilidad.

A modo de conclusión, tan sólo decir que el trabajo social en la empresa privada constituye un verdadero reto en la actualidad.

A lo largo de este artículo hemos querido reflejar cuál podría ser el papel de un trabajador social en la empresa, señalando algunas de las funciones que podría desempeñar. También, destacar cuál es la problemática planteada en las empresas, problemática a la que no se suele dar una solución profesional, solución que ayude tanto a empresarios como a trabajadores.

Somos conscientes de nuestra limitación a la hora de escribir este artículo, así como de la implantación de algunas de las ideas en él recogidas, dada la actual situación de la política de nuestras empresas. Esperemos que las cosas cambien. 